\title{
Sistem Informasi Pembelian Stok Barang Pada Toko Anguang Dengan Metode EQQ
}

\author{
Aggry Saputra ${ }^{1}$, Saharudin $^{2}$, Meri $^{3}$ \\ 1,3 Jurusan Teknik Informatika STT Indonesia Tanjungpinang \\ Jln. Pompa Air No. 28 Tanjungpinang Kepulauan Riau Indonesia \\ 11aggrysaputra@gmail.com, ${ }^{2}$ saharoedin.official@gmail.com, ${ }^{3}$ mer1_ng23@yahoo.com
}

\begin{abstract}
Intisari- Toko Anguang adalah Toko yang bergerak di bidang dagang menjual barang-barang sembako. Pengolahan data yang digunakan Toko Anguang saat ini masih menggunakan sistem penyimpanan secara manual, seperti dalam proses merekap pembelian penjualan, termasuk juga dalam membuat laporan bulanan masih dilakukan secara manual. Penerapan pengendalian sediaan sangat penting bagi badan usaha yang bertujuan untuk mendukung pengambilan keputusan organisasi agar didapatkan sediaan yang optimal. Permintaan yang tinggi terhadap barang membutuhkan pengendalian sediaan yang tepat karena organisasi mengeluarkan biaya yang sangat besar untuk sediaan. Sehingga dengan sistem yang ada saat ini dirasa kurang efektif dan kurang efisien, karena sering terjadi kesalahan saat melakukan rekap pembelian. Berdasarkan permasalahan yang ada, penulis melakukan analisa dan merancang sistem baru yang mengantisipasi kelemahan-kelemahan pada sistem yang berjalan tanpa menimbulkan permasalahan-permasalahan baru.

Kata kunci - pembelian, efisien, sistem informasi.
\end{abstract}

\begin{abstract}
Anguang's Store is Commercials selling goods for groceries. processing of the data used Anguang's Store today still uses the storage system manually, as in the process of purchasing recap, sales, and on improvements, as well as in making a monthly report still done manually. Application control of dosage is essential for enterprises that aim to support decision making in the organization in order to get the optimal dosage. High demand for generator sets require precise control of dosage because organizations pay a very large dosage So that the current system is deemed less effective and less efficient, because it often goes wrong while doing a recap of the purchase. Based on the existing problems, the authors analyze and design new systems that anticipate weaknesses in existing systems without causing new problems.
\end{abstract}

Keywords - purchasing, efficient, information system.

\section{Pendahuluan}

Akuntansi memegang peranan yang sangat penting dalam setiap usaha baik dalam usaha berskala kecil maupun berskala besar, karena akuntansi memberikan informasi keuangan yang kualitatif dan kuantitatif kepada pihak-pihak yang berkepentingan agar memperoleh suatu dasar, guna bermanfaat jika diperoleh hasil akuntansi yang baik dan mampu memberikan gambaran yang wajar tentang keuangan dan aktivitas perusahaan yang akhirnya disajikan dalam bentuk laporan keuangan.

Toko Anguang merupakan suatu usaha yang bergerak dalam bidang usaha dagang. Toko Anguang ini dalam melakukan pencacatan pembelian dan penjualan masih manual, sehingga data keuangan yang ada kurang akurat. Jika pemilik ingin mengetahui perkembangan usahanya dan mengetahui keuntungan atau laba yang diperoleh pada saat tertentu, pihak administrasi akan memerlukan waktu yang relatif lama untuk menghitungnya.

Terlebih lagi untuk pengambilan keputusan penambahan stok barang, perlu dilakukan penghitungan manual yang memakan waktu cukup lama sehingga kinerja administrasi dapat dirasakan kurang maksimal. Seiring dengan semakin pesatnya perkembangan teknologi informasi banyak perusahaan kecil maupun besar yang menggunakan komputer sebagai alat bantu dalam pengolahan data mereka agar didapatkan kemudahan dalam pencatatan transaksi serta operasi-operasi yang mendukung sehingga menghasilkan laporan keuangan yang akurat, cepat, obyektif dan tepat waktu, maka diusulkan untuk membangun suatu perangkat lunak yang bersifat dinamis dan memiliki kemampuan untuk mengolah data dan penentuan keputusan penambahan stok yang dibutuhkan oleh penjualan sembako.

\section{Metodologi Penelitian}

\section{A. Metode Pengumpulan Data}

Metodologi pengumpulan data yang digunakan dalam pembuatan skripsi ini adalah :

1) Studi Pustaka

Untuk pembuatan dan penelitian proyek ini dilakukan dengan cara mencari data dan teori dari buku-buku dan referensi yang berhubungan dengan pembahasan dan topik dari proyek tersebut. Diharapkan studi ini bisa menjadi landasan dalam penyusunan proyek ini.

2) Studi Lapangan

Studi lapangan dilakukan dengan cara melibatkan perusahaan secara langsung. Hal ini dilakukan untuk mendapatkan data-data dan keterangan-keterangan yang berhubungan dengan masalah-masalah yang diteliti. Studi lapangan meliputi:

a. Observasi

Observasi yaitu melakukan pengamatan secara langsung terhadap objek yang diteliti untuk mendapatkan data dan informasi yang diperlukan sesuai dengan permasalahan. 


\section{B. Metode Pengembangan Sistem}

Metode pengembangan sistem yang digunakan adalah pendekatan terstruktur atau waterfall yang terdiri dari beberapa tahap kegiatan yaitu :

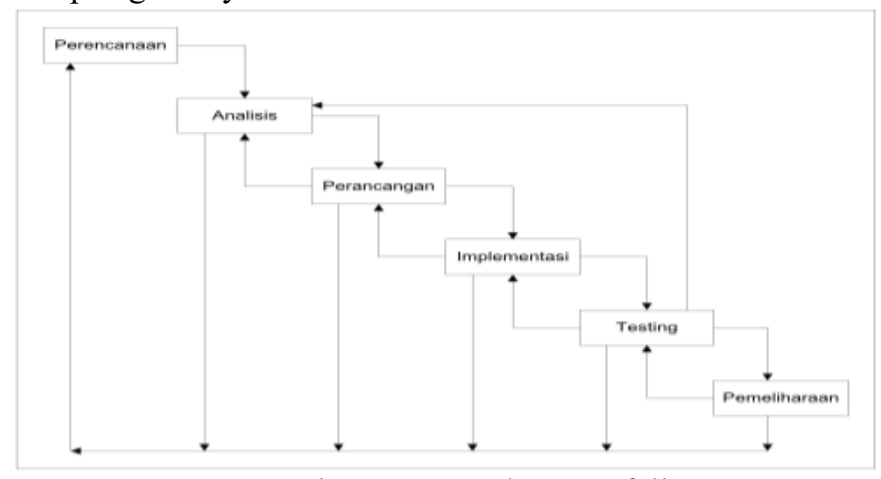

Gambar 1.1 Metode Waterfall 1

Keterangan :

1) Perencanaan (system engineering) adalah tahapan menangani masalah perangkat lunak, perangkat keras dan sumber daya manusia.

2) Analisis (analysis) adalah melakukan analisis sistem dengan mencari penyebab-penyebab masalah yang timbul di sistem lama untuk diidentifikasikan permasalahannya dan digunakan sebagai dasar perancangan sistem baru.

3) Perancangan (design) adalah proses mengubah kebutuhan-kebutuhan menjadi bentuk karakteristik yang dimulai dengan penulisan program desain tadi harus diubah menjadi bentuk yang dimengerti sistem.

4) Implementasi (implementation) adalah tahap penerjemahan desain kedalam bahasa pemrograman yang sesuai dengan kebutuhan.

5) Pengujian (testing) adalah tahap pengujian perangkat lunak yang telah dikembangkan untuk mengcover kesalahan-kesalahan dan menjamin bahwa masukan sesuai dengan hasil yang dibutuhkan.

6) Pemeliharan (maintenance) adalah tahap perawatan sistem yang telah dikembangkan seperti perangkat lunak, perangkat keras dan media lain yang berhubungan dengan komputer. Pada tahap ini segala kemungkinan mengenai kekurangan perangkat lunak baik berupa kesalahan atau hal-hal yang ditambahkan kedalam perangkat lunak.

\section{Metode EOQ (Economic Order Quantity)}

Setiap perusahaan selalu berusaha untuk menentukan policy penyediaan bahan dasar yang tepat, dalam arti tidak mengganggu proses produksi dan disamping itu biaya yang ditanggung tidak terlalu tinggi. Untuk keperluan itu terdapat suatu metode EOQ (Economic Order Quantity).

Menurut Gitosudarmo (2002:101) EOQ sebenarnya adalah merupakan volume atau jumlah pembelian yang paling ekonomis untuk dilaksanakan pada setiap kali pembelian. Untuk memenuhi kebutuhan itu maka dapat diperhitungkan pemenuhan kebutuhan (pembeliannya) yang paling ekonomis yaitu sejumlah barang yang akan dapat diperoleh dengan pembelian dengan menggunakan biaya yang minimal.

EOQ (Economic Order Quantity) adalah jumlah pesanan yang dapat meminimumkan total biaya persediaan, pembelian yang optimal. Untuk mencari berapa total bahan yang tetap untuk dibeli dalam setiap kali pembelian untuk menutup kebutuhan selama satu periode. (Yamit, 1999:47)

\section{HASIL DAN PEMBAHASAN}

Hasil penelitian hendaknya dijelaskan secara jelas dan padat. Diskusi hendaknya menguraikan arti pentingnya hasil penelitian, bukan mengulanginya. Hindari penggunaan sitasi dan diskusi yang berlebihan tentang literatur yang telah dipublikasikan.

\section{A. Analysis Procedure}

Tinjauan prosedur yang sedang berjalan untuk mengetahui tata kerja dalam mengolah data dalam sebuah organisasi. Dengan menjalankan prosedur yang sedang berjalan dapat mengetahui langkah-langkah aktivitas dalam melaksanakan suatu kegiatan. Prosedur pengolahan data jual beli pada sistem yang berjalan dapat dijelaskan berdasarkan intensitas adalah sebagai berikut :

1) Flowmap yang sedang berjalan pada proses pembelian:

a. Admin melakukan pengecekan barang dan pengecekan ketersediaan akan barang.

b. Jika ketersediaan barang mencukupi, maka proses berhenti sampai di sini, namun jika ketersediaan barang dianggap kurang, maka admin akan membuat form permintaan pembelian barang.

c. Dari form permintaan pembelian barang, admin akan mencari supplier dan memberikan form tersebut.

d. Jika supplier tidak memiliki ketersediaan barang yang dibutuhkan, proses kembali ke tahap c.

e. Jika supplier memiliki ketersediaan barang, maka supplier akan membuat nota pembelian dan memberikan barang yang dibutuhkan kepada admin.

f. Admin akan mencatat penambahan stok ketersediaan barang dari barang yang dibeli. Dan berdasarkan nota pembelian, admin membuat laporan pembelian yang akan diserahkan kepada pemilik, dan nota pembelian tersebut diarsipkan oleh admin. 


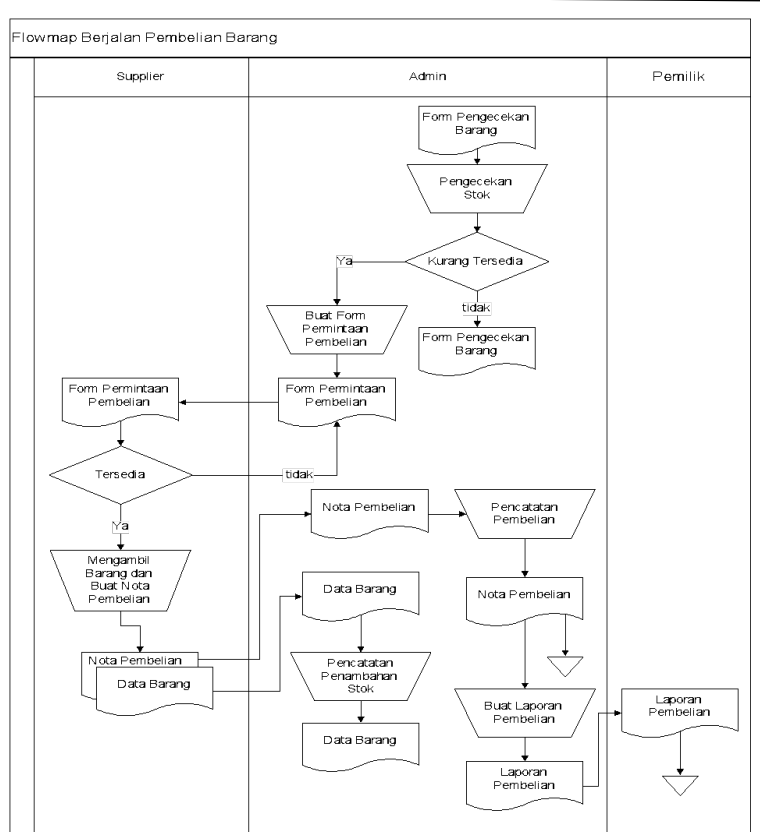

Gambar 3.1 Flowmap Berjalan Pembelian Barang

2) Flowmap yang sedang berjalan atas penjualan:

a. Konsumen memberikan permintaan barang yang diinginkan kepada admin.

b. Admin akan memeriksa permintaan barang dalam ketersediaan stok barang tersebut.

c. Jika tidak tersedianya stok akan barang tersebut, maka maka admin tidak menyetujui permintaan barang tersebut.

d. Namun, jika barang tersedia, admin akan membuat 2 (dua) rangkap nota penjualan dan mengambil barang yang diinginkan konsumen.

e. Admin memberikan barang dan satu rangkap nota penjualan kepada konsumen.

f. Dari satu rangkap nota penjualan lagi, admin akan mengarsipkan nota penjualan itu. Dan membuat laporan penjualan yang akan diberikan kepada pemilik toko.

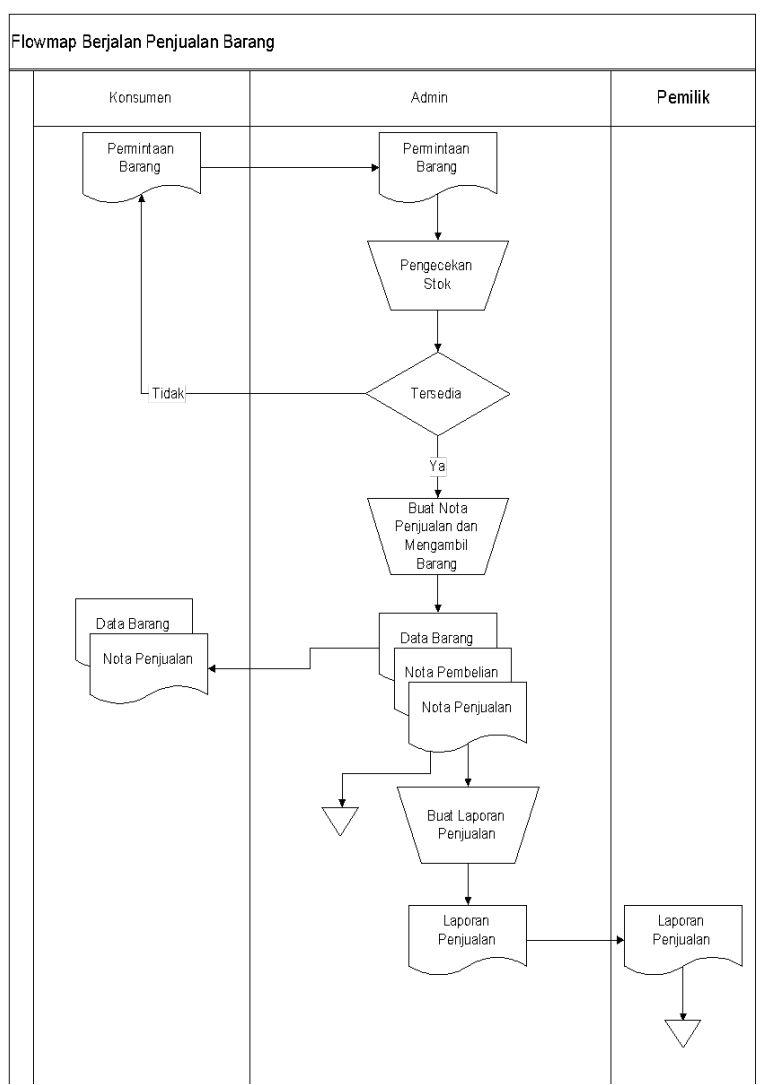

Gambar 3.2 Flowmap Berjalan Penjualan Barang

\section{B. Analisis Kelemahan Sistem}

Analisa kelemahan sistem ini bertujuan untuk memperbaiki kelemahan yang ada tentang penerapan pengolahan data jual beli di Toko Anguang. Adapun beberapa kelemahan terdapat didalamnya yaitu:

1) Dibutuhkan penghitungan ulang secara manual untuk menentukan harus membeli seberapa banyak stok barang untuk disimpan.

2) Pada saat selesai proses pembelian dan penjualan tetap harus melakukan penghitungan ulang lagi untuk cek kondisi dan jumlah barang.

3) Pembuatan laporan yang ada memerlukan waktu yang cukup lama dikarenakan harus merekap ulang setiap kali akan membuat laporan.

\section{Analisis Dokumen}

Aliran dokumen menggambarkan bagaimana dan untuk apa saja dokumen - dokumen itu digunakan dalam sistem. Untuk itu Analisis dokumen merupakan salah satu cara yang dapat membantu dalam proses perancangan sistem selanjutnya.

Dari hasil survei yang dilakukan pada Toko Anguang diperoleh beberapa dokumen, yaitu :

1) Dokumen Masukan

a. Nota Pembelian

$\begin{array}{ll}\text { Sumber } & \text { : Supplier } \\ \text { Tujuan } & \text { : Admin } \\ \text { Fungsi } & \text { : Sebagai bukti pembelian barang } \\ \text { Rangkap } & : \text { 1 (satu) }\end{array}$

2) Dokumen Keluaran

a. Nota Penjualan Barang

Sumber : Admin 


\begin{tabular}{|c|c|c|}
\hline & Tujuan & : Konsumen \\
\hline & Fungsi & : Sebagai bukti penjualan barang \\
\hline & Rangkap & $: 1$ (satu) \\
\hline \multirow[t]{5}{*}{ a. } & Permintaan & Barang \\
\hline & Sumber & : Admin \\
\hline & Tujuan & : Supplier \\
\hline & Fungsi & $\begin{array}{l}\text { : Sebagai form permintaan barang } \\
\text { yang ingin dibeli }\end{array}$ \\
\hline & Rangkap & $: 1$ (satu) \\
\hline
\end{tabular}

\section{Analisis Metode EQQ}

Kontinuitas usaha atau kelangsungan hidup perusahaan merupakan salah satu aspek yang penting untuk diketahui oleh pihak - pihak yang berkepentingan dalam perusahaan. Meramalkan kelangsungan hidup perusahaan penting karena faktanya tidak satupun pihak dalam perusahaan mengharapkan akan terjadinya kebangkrutan atau menutup usaha pada suatu waktu mendatang.

\section{1) Contoh Kasus Metode $\boldsymbol{E O}$}

Toko Anguang pada tahun yang akan datang membutuhkan bahan baku sebanyak 240.000 Unit. Harga bahan baku per unit Rp2.000. biaya pesan untuk setiap kali melakukan pemesanan sebesar Rp150.000, sedangkan biaya penyimpanan sebesar $25 \%$ dari nilai rata - rata persediaan.

\section{Diminta :}

a. berapa jumlah pemesanan yang paling ekonomis ( EOQ)?

b. berapa kali pemesanan yang harus dilakukan dalam setahun?

c. berapa hari sekali perusahaan melakukan pemesanan $(1$ tahun $=360$ hari $)$ ?

d. apabila waktu yang dibutuhkan dari saat memesan sampai bahan baku tiba di perusahaan adalah 2 minggu, kapan perusahaan harus melakukan pemesanan kembali (Reorder Point).

Jika diasumsikan 1 tahun $=50$ Minggu.

Jawab :

a.
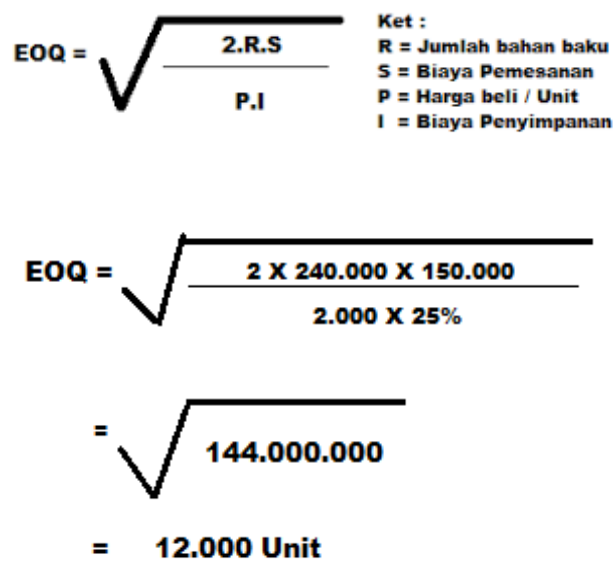

b. Pemesanan yang dilakukan dalam setahun $=$ $240.000 / 12.000=20 \times$ pemesanan. c. Jika 1 tahun $=360$ hari, maka pemesanan dilakukan $=360 / 20=18$ Hari Sekali

ROP = Penggunaan bahan rata $2 /$ hari $x$ lead time $x$ safety Stook

\section{2) Contoh Kasus II}

Sebuah toko pusat oleh-oleh khas Banyumas yang bernama "Pusat Keripik Trisoda" yang berada di lokawisata Baturaden mampu menjual keripik pisang rata-rata 50 bungkus perharinya. Besar permintaan tersebut diperkirakan konstan setiap harinya. Pihak manajemen toko menetapkan melakukan pemesanan ke bagian produksi sebesar 3000 bungkus setiap kali pemesanan dengan waktu tunggu 6 hari dengan biaya Rp200.000,- dalam sekali pemesanan. Biaya penyimpanan per bungkus keripik pisang adalah sebesar Rp5.000,-. Jika toko tersebut menerapkan sistem 30 hari kerja per bulan, tentukan biaya minimum tahunan yang harus dikeluarkan dan siklus pemesanan kembali yang harus diterapkan oleh toko tersebut!

\section{Penyelesaian:}

Diketahui:

$\mathrm{R}=$ jumlah permintaan per tahun

$=50 \times 30 \times 12$

$=18000$ bungkus

$\mathrm{S}=$ biaya pemesanan

$=\mathrm{Rp} 200.000$,-

$\mathrm{C}=$ biaya penyimpanan per tahun

$=$ Rp5.000,- per bungkus

$\mathrm{ROP}=$ penjualan rata-rata per hari $\times$ lead time

$=50 \times 6$

$=300$ bungkus

Dari parameter yang diketahui, diperoleh siklus pemesanan awal (belum optimal) seperti berikut:

Perhitungan:

$\mathrm{EOQ}=\mathrm{Q}^{*}=\sqrt{2} \mathrm{RSC}$

$=\sqrt{ } 2 \times 18000 \times 2000005000$

$=1200$ bungkus

TOC $=$ total biaya pemesanan per tahun

$=\left(\mathrm{RQ}^{*}\right) \mathrm{S}$

$=(180001200) 200000$

$=\mathrm{Rp} 3.000 .000$,-

TCC $=$ total biaya penyimpanan per tahun

$=(\mathrm{Q} * 2) \mathrm{C}$

$=(12002) 2000$

$=\mathrm{Rp} 1.200 .000$,-

$\mathrm{TAC}=$ total biaya tahunan minimum

$=\mathrm{TOC}+\mathrm{TCC}$

$=3.000 .000+1.200 .000$ 
$=\mathrm{Rp} 4.200 .000,-$

$\mathrm{F}^{*}=$ frekuensi pemesanan optimum per tahun

$=\mathrm{RQ}^{*}$

$=180001200$

$=15$ pemesanan per tahun

$\mathrm{T}^{*}=$ jarak siklus optimum

$=(\mathrm{Q} * \mathrm{R}) \times$ jumlah hari kerja per tahun

$=(120018000) \times 360$

$=24$ hari

Dari hasil perhitungan, diperoleh siklus pemesanan optimal sebagai berikut:

\section{Kesimpulan:}

Jadi, untuk memperoleh hasil yang optimum pihak manajemen toko "Pusat Kripik Trisoda" harus mengeluarkan biaya tahunan minimum sebesar Rp 4.200.000,- dan melakukan pemesanan keripik pisang ke bagian produksi sebanyak 1.200 bungkus setiap 24 hari kerja, yaitu pada saat persediaan tinggal 300 bungkus.

\section{KESIMPULAN}

A. Kesimpulan

Setelah merancang dan membuat sistem informasi penjualan pada toko Anguang ini, penulis telah dapat menyimpulkan beberapa hal diantaranya sebagai berikut :

1) Dengan adanya aplikasi ini dapat membantu secara komputerisasi dalam mengelola data untuk data pembelian, sehingga lebih mudah dan cepat.

2) Dapat menyimpan semua data secara teratur ke dalam satu database sehingga tidak menimbulkan kehilangan data seperti sebelumnya, dimana penyimpanan data masih tersimpan secara manual / buku.

3) Dapat mempermudah dalam pembuatan laporan dan mempercepat hal pencarian data baik itu berupa laporan untuk data penjualan dan data pembelian.

4) Telah menerapkan penghitungan persediaan dengan metode economic order quantity yang berguna untuk mengetahui tingkat kemungkinan peningkatan atau penurunan untuk pemesanan persediaan barang pada periode selanjutnya.

5) Telah menerapkan penghitungan persediaan dengan metode economic order quantity secara terkomputerisasi.

B. Saran

Setelah melakukan penelitian dan pengerjaan pembuatan sistem terdapat beberapa saran, yaitu :

1) Diadakan pelatihan atau training pada karyawan mengenai aplikasi yang baru ini.

2) Dalam perhitungan dibutuhkannya ketelitian dalam mengolah data-data, agar tidak terjadi kesalahan dalam perhitungan.

3) Diharapkan aplikasi ini dapat dikembangkan terus sesuai dengan kebutuhan user.
4) Diharapkan mencoba penghitungan persediaan dengan

\section{UCAPAN TERIMA KASIH}

Puji Syukur atas kehadirat Tuhan Yang Maha Esa atas berkat rahmat dan karunia-Nya penulis dapat menyelesaikan Skripsi dengan Judul "SISTEM INFORMASI PEMBELIAN STOK BARANG DENGAN METODE EOQ PADA TOKO ANGUANG TANJUNGPINANG".

Penulis menyadari bahwa Skripsi ini tidak mungkin selesai tanpa bimbingan dan bantuan secara langsung maupun tidak langsung dari berbagai pihak. Pada kesempatan ini penulis ingin mengucapkan terima kasih yang sebesar-besarnya kepada

1. Bapak HM. Louis Frederick, SE, SH, MM selaku Ketua Sekolah Tinggi Teknologi Indonesia Tanjungpinang.

2. Bapak Drs. H Mohd.Saleh H. Umar, MM,selaku Ketua Harian Sekolah Tinggi Teknologi Indonesia

3. Wakil Ketua I Bidang Akademik

4. Wakil Ketua II Bidang Administrasi Umum dan Keuangan

5. Bapak Mochammad Rizki Romdoni, S.Kom, MT selaku dosen pembimbing yang dengan sabarnya telah memberikan bimbingan untuk penulis dari awal hingga akhir skripsi ini.

6. Orang Tua yang selalu mendukung penulis dalam keadaan apapun.

7. Teman-teman serta Alumni yang telah membantu penulis agar selesainya skripsi ini.

Penulis menyadari skripsi ini masih banyak kekurangan dan masih jauh dari sempurna. Mengingat kurangnya pengetahuan dan pengalaman penulis, maka dengan kerendahan hati penulis mengharapkan adanya saran dan kritikan yang sifatnya membangun dari semua pihak demi penyempurnaan skripsi ini.

Akhirnya tidak lupa pula penulis mengucapkan terimakasih sebesar-besarnya kepada semua pihak yang telah membantu dalam menyelesaikan skripsi ini, penulis berharap skripsi ini bermanfaat bagi para pembaca.

\section{REFERENSI}

[1] Andri, Kristanto.2003.Perancangan Sistem Informasi. Cawamedia, Yogyakarta

[2] Ir. H. Lili asdjudiredja, SE.1999.Manajemen Produksi.ARNICO, Jakarta

[3] Gorden B Davis.1991.Kerangka Dasar Sistem Informasi Manajemen Bagian 1. Pustaka Bina Mas Press Indo, Jakarta

[4] Charles Thomas Horngren dan Walter T Harrison.1992.book accounting.Erlangga,Jakarta

[5] Herjanto.1997.Manajemen Operasi Edisi 3.PT Grasindo, Jakarta

[6] Depdiknas.2008.Kamus Besar Bahasa Indonesia Pusat Bahasa Edisi 4.PT. Gramedia Pustaka Utama,Jakarta

[7] Prawirosentono, Suyadi.2002.Manajemen Sumber Daya Manusia: Kebijakan, Kinerja Karyawan Edisi 1. BPFE Jogjakarta, Jogjakarta

[8] Riyanto, Bambang. 2001. Dasar-Dasar Pembelanjaan Perusahaan. BPFE, Jogjakarta

[9] Soemarsono.1999. Akuntansi Suatu Pengantar Buku 1 Edisi 4.Rineka Cipta, Jakarta

[10] Swastha Basu.1998.Azas-Azas Marketing. Liberty Jogjakarta, Jogjakarta 